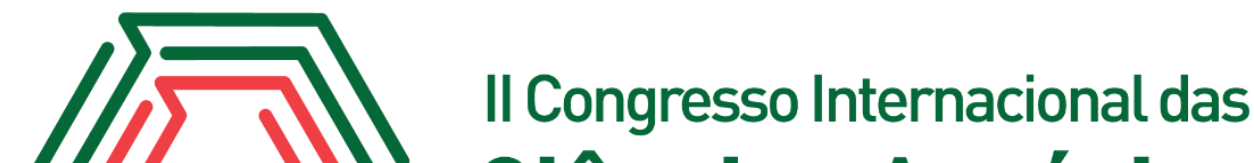 Ciências Agrárias COINTER - PDVAgro 2017
}

\section{INDICADORES DA FERTILIDADE DO SOLO EM SISTEMAS DE PLANTIO DIRETO E VEGETAÇÃO NATIVA DE CERRADO}

\author{
Apresentação: Pôster \\ Wesley dos Santos Souza ${ }^{1}$; Patricia Carvalho da Silva ${ }^{2}$; Taiwan Carlos Alves Menezes ${ }^{3}$; \\ Jenilton Gomes da Cunha ${ }^{4}$; Manoel Ribeiro Holanda Neto ${ }^{5}$
}

\section{Introdução}

A preocupação com a avaliação da qualidade do solo tem merecido destacada atenção, e a quantificação de alterações nos seus atributos, decorrentes da intensificação de sistemas de uso e manejo, tem sido amplamente realizada para monitorar a produtividade sustentável dos solos (NEVES et al., 2007) e a conservação dos recursos naturais.

O uso do solo, com o passar do tempo, conduz a aumento na sua heterogeneidade, por meio do processo de desmatamento, preparo do solo, rotações de cultura, localização de aplicação de fertilizantes, como estes são aplicados em faixas ou em linhas, isso faz com que o sistema de amostragem varie consideravelmente. O uso sustentável dos recursos naturais, especialmente do solo e da água, tem vindo a crescer como tema relevante, principalmente devido ao aumento de atividades antrópicas, considerando que a manutenção da qualidade desses recursos é essencial para o crescimento e desenvolvimento de plantas e sustentabilidade dos sistemas agrícolas (ARAÚJO et al., 2010).

Devido à importância significativa dos atributos químicos na qualidade do solo, das plantas e do ecossistema como um todo, o presente trabalho teve como objetivo avaliar a interferência do manejo adotado em áreas de cultivo do cerrado na fertilidade do solo, com o intuito de elucidar a sustentabilidade dos sistemas nestas áreas.

\footnotetext{
${ }^{1}$ Mestrado em Ciência do Solo, Universidade Federal do Ceará, agrowesley95@gmail.com

${ }^{2}$ Mestrado em Produção Sustentável, Universidade de Brasília, patriciacarvalhoagro@gmail.com

${ }^{3}$ Eng. Agrônomo, Universidade Estadual do Piauí, taiwanallves@hotmail.com

${ }^{4}$ Metrado em Produção Vegetal, Universidade Federal do Vale do São Francisco, jeniltongomes@hotmail.com

${ }^{5}$ Professor Assistente I-DE, Universidade Estadual do Piauí, mrholandaneto@hotmail.com
} 


\section{Fundamentação Teórica}

O preparo convencional do solo em sendo substituído pelos sistemas conservacionistas de manejo, como plantio direto, em que se mantém a estrutura do solo preservada, a redução da mobilização e a manutenção da cobertura do solo, com isso a utilização desse sistema de produção tem evoluído significativamente em termos de área cultivada no Brasil (SILVA et al., 2000). Quando uma área de vegetação nativa de cerrado é convertida em pastagem, ou área de cultivo de grãos, os atributos químicos do solo são alterados (CARNEIRO et al. 2009).

No Brasil essa crescente é relevante, sendo uma grande conquista para o país, pois sob plantio direto a perda de solo por erosão é reduzida e o estoque de Matéria Orgânica do Solo (MOS) aumenta, mudanças que melhoram a qualidade, fertilidade do solo e a eficiência de uso da água e dos nutrientes pelas plantas, mas dependem do não revolvimento do solo, do nível de acúmulo de palha, de modificações na fertilidade do solo, da variabilidade de espécies na rotação, da dinâmica da água no solo e da dinâmica de pragas, doenças e plantas invasoras (LOPES et al., 2004). Assim, de acordo com Kramer, (2012), em áreas com vários anos de adoção de sistema de plantio direto é comum identificar talhões ou partes de talhões (zonas uniformes) com produtividades distintas, mesmo com culturas e condições climáticas semelhantes ao longo do tempo.

\section{Metodologia}

O estudo foi desenvolvido em áreas de produtores de grãos no cerrado da região nordeste, município de Formosa do Rio Preto - BA. Os solos das áreas foram classificados como Latossolos Amarelos, textura franco argilo-arenosa (SANTOS et al., 2013). O clima da região é do tipo Aw no sistema de Koppen, com temperatura média de $26,5^{\circ} \mathrm{C}$, precipitação anual de $1.200 \mathrm{~mm}$, com estação chuvosa nos meses de outubro a abril, sendo o trimestre mais chuvoso concentrado entre janeiro e março (MATIAS, 2006).

Em cada sistema e na área de referência (VNC) coletou-se amostras de solo nas profundidades de 0-5, 5-10 e 10-20 cm. Foram estudados quatro sistemas de manejo do solo: Sistema Plantio Direto, um ano de adoção com Soja mais Milheto (SPD1+SM ${ }^{1}$ ); Sistema de Plantio Direto 03 (três) anos de adoção com braquiária como cultura de cobertura e rotação de cultivo soja/milho nos últimos três anos (SPD3+B); Sistema de Plantio Direto 6 (seis) anos de adoção com braquiária como cultura de cobertura e rotação de cultivo milho/braquiária no último ano 
(SPD6+M $\left.{ }^{2} \mathrm{~B}\right)$; Sistema de plantio direto 6 (seis) anos de adoção com rotação soja/braquiária/milho/braquiária (SPD6+SB), além de uma área sob Vegetação Nativa de Cerrado (VNC), como referência de "um ambiente em condição de equilíbrio".

A quantificação da acidez trocável $\left(\mathrm{Al}^{+3}\right)$, acidez potencial $(\mathrm{H}+\mathrm{Al})$, do Fósforo, Potássio, Cálcio, Magnésio foram determinados de acordo com Donagema et al.,2011. A Soma de Bases (SB) foi obtida pela expressão: $\mathrm{SB}=\mathrm{Ca}^{+2}+\mathrm{Mg}^{+2}+\mathrm{K}^{+}\left(\mathrm{Cmol}_{\mathrm{c}} \mathrm{dm}^{-3}\right)$. A Capacidade de Troca de Cátions (CTC) determinadas pela expressão: $\mathrm{CTC}=\mathrm{Ca}^{+2}+\mathrm{Mg}^{+2}+\mathrm{K}^{+}+\mathrm{H}^{+}+\mathrm{Al}^{+3}\left(\mathrm{Cmol}_{\mathrm{c}} \mathrm{dm}^{-3}\right)$. A Saturação de Bases (V\%) obtida pela expressão: V\% $=(\mathrm{SB} / \mathrm{CTC}) \times 100, \mathrm{em}^{\mathrm{Cmol}} \mathrm{c} \mathrm{dm}^{-3}$.

O delineamento experimental utilizado foi o Inteiramente Casualizado (DIC) por parcelas subdivididas, com quatro repetições (trincheiras). Os efeitos dos tratamentos nas variáveis respostas foram avaliados pela ANOVA e médias comparadas pelo teste de Tukey a 5\% de probabilidade, utilizando o programa computacional Assistat 7.7.

\section{Resultados e Discussões}

Os valores de Soma de Bases, CTC e V\% obtiveram diferença estatística entre os sistemas e apresentaram valores superiores a área referência com Vegetação Nativa de Cerrado (Tabela 1).

Tabela 1: Influência de Sistema de Plantio Direto sob os teores de Soma de Bases (SB), Capacidade de Troca de Cátions (CTC) e Saturação por Bases (V\%). Fonte: Própria

\begin{tabular}{cccccc}
\hline \multirow{2}{*}{ Profundidade } & \multicolumn{5}{c}{ Tratamentos } \\
\cline { 2 - 6 } & VNC & SPD1+SM & SPD3+B & SPD6+M ${ }^{2} \mathrm{~B}$ & SPD6+SB \\
\hline & \multicolumn{5}{c}{ SB $\left(\mathrm{Cmol}_{\mathrm{c}} \mathrm{dm}^{-3}\right)$} \\
$5-5 \mathrm{~cm}$ & $1,27 \mathrm{cA}$ & $4,09 \mathrm{bA}$ & $5,94 \mathrm{aA}$ & $5,70 \mathrm{abA}$ & $5,79 \mathrm{aA}$ \\
$10-20 \mathrm{~cm}$ & $1,20 \mathrm{bA}$ & $3,60 \mathrm{aAB}$ & $3,49 \mathrm{aB}$ & $3,84 \mathrm{aB}$ & $3,03 \mathrm{aB}$ \\
$0-5 \mathrm{~cm}$ & $0,86 \mathrm{bA}$ & $2,60 \mathrm{aB}$ & $2,18 \mathrm{abB}$ & $2,69 \mathrm{aB}$ & $2,73 \mathrm{aB}$ \\
\hline $5-10 \mathrm{~cm}$ & $8,66 \mathrm{bA}$ & $8,68 \mathrm{bA}$ & $9,30 \mathrm{abA}$ & $10,85 \mathrm{aA}$ & $8,59 \mathrm{bA}$ \\
$10-20 \mathrm{~cm}$ & $7,44 \mathrm{bAB}$ & $8,05 \mathrm{abA}$ & $8,70 \mathrm{abAB}$ & $9,97 \mathrm{aAB}$ & $7,68 \mathrm{bA}$ \\
$0-5 \mathrm{~cm}$ & $6,30 \mathrm{bB}$ & $8,41 \mathrm{abA}$ & $7,85 \mathrm{abB}$ & $9,32 \mathrm{aB}$ & $7,78 \mathrm{abA}$ \\
\hline $5-10 \mathrm{~cm}$ & $14,55 \mathrm{dA}$ & $47,45 \mathrm{cA}$ & $63,80 \mathrm{abA}$ & $51,81 \mathrm{bcA}$ & $68,00 \mathrm{aA}$ \\
$10-20 \mathrm{~cm}$ & $15,77 \mathrm{bA}$ & $44,67 \mathrm{aA}$ & $40,79 \mathrm{aB}$ & $37,87 \mathrm{aB}$ & $39,56 \mathrm{aB}$ \\
\hline
\end{tabular}

Medias seguidas de mesma letra minúscula, na linha e maiúscula, na coluna não diferem estatisticamente em si pelo teste de Tukey a 5\% de probabilidade. Vegetação Nativa de Cerrado (VNC); Sistema Plantio Direto, um ano de adoção com Soja/ Milheto (SPD1+SM ${ }^{1}$ ); Sistema de Plantio Direto três anos de adoção com braquiária e rotação soja/milho (SPD3+B Sistema de plantio direto 6 (seis) anos de adoção com rotação soja/braquiária/milho/braquiária (SPD6+SB). 
Os menores valores de todos atributos analisados e resultados da V\% abaixo de $50 \%$ na Vegetação Nativa evidenciam um caráter distrófico do solo do Cerrado, o que confirma que essas áreas possuem baixa fertilidade natural, o que pode ser justificado pelo fato de a maior parte dessas áreas de cerrado possuir predominância de Latossolos, profundos, bastante intemperizados, ácidos (Leite et al., 2010). Os maiores valores de soma de bases saturação nos sistemas de plantio direto, foi ocasionado pela influência do manejo da fertilidade do solo, pelas adubações e correções realizadas nestes sistemas.

Observou-se também maiores valores de todos os atributos avaliados nos sistemas de plantio direto na camada superficial $(0-5 \mathrm{~cm})$, este resultado pode estar associado à aplicação localizada de fertilizantes sem incorporação e principalmente devido a predominância de palhada dos resíduos vegetais das culturas de coberturas, que podem possibilitar uma retenção de nutrientes nos tecidos vegetais e posterior disponibilização destes ao solo, predominantes nas camadas superficiais do solo, devido ao não revolvimento do solo, evitando desta forma que grande parte dos nutrientes sejam distribuídos na camada arável do solo e lixiviados.

\section{Conclusões}

Se torna necessária para a melhoria da fertilidade dos solos do cerrado e posterior realização do cultivo a aplicação de corretivos e adubos nessas áreas, visto que são áreas que possuem uma baixa fertilidade natural.

As camadas mais superficiais dos sistemas de plantio direto possuem a maior fertilidade que as camadas mais profundas, estando isso aliado ao não revolvimento do solo juntamente com o fornecimento de nutriente pelos resíduos vegetais das culturas que se encontram na superfície do solo.

\section{Referências}

ARAúJO, F. S.; SAlviano, A. A. C.; LeITE, L. F. C.; SOUZA, Z. M.; SOUSA, A. C. M. Physical quality of a yellow Latossol under integrated crop-livestock system. Revista Brasileira de Ciência do Solo, Viçosa, v.34, n. 3, p. 717-723, 2010.

CARNEIRO, M. A. C.; SOUZA, E. D.; REIS, E. F.; PEREIRA, H.S.; H. S.; AZEVEDO, W. R. Atributos físicos, químicos e biológicos de solo de cerrado sob diferentes sistemas de uso e manejo. Revista Brasileira de Ciência do Solo, Viçosa, v. 33, n. 1, p. 147-157, 2009. 
DONAGEMA, G.K.; CAMPOS, D.V.B. de; CALDERANO, S.B.; TEIXEIRA, W.G.; VIANA, J.H.M. (Org.). Manual de métodos de análise de solos. 2.ed. rev. Rio de Janeiro, Embrapa Solos, 2011, 230p.

KRAMER, L. F. M. Atributos químicos e físicos de um latossolo sob plantio direto em zonas de manejo com diferentes produtividades. 2012.f. Dissertação (mestrado) - Universidade Estadual do Centro-Oeste, Programa de Pós-Graduação em Agronomia, área de concentração em Produção Vegetal, 2012.

LEITE, L.F.C.; GALVÃO, S.R.S.; HOLANDA NETO, M.R. et al. Atributos químicos e estoques de carbono em Latossolo sob plantio direto no cerrado do Piauí. Revista Brasileira de Engenharia Agrícola e Ambiental - Agriamb, v.14, n.12, p.1273-1280, 2010.

LOPES, A.S.; WIETHÖLTER, S.; GUIMARÃES GUILHERME, L.R.; SILVA, C.A. Sistema Plantio Direto: bases para o manejo da fertilidade do solo. São Paulo: ANDA - Associação Nacional para Difusão de Adubos, 2004. 115p.

MATIAS, M. C. B. S. Atributos químicos e biológicos de um Latossolo Amarelo sob diferentes sistemas de manejo dos Cerrados do Piauí. 2006. f. 47. Dissertação (Mestrado em Agronomia) Programa de Pós-Graduação em Agronomia, Universidade Federal do Piauí.

NEVES, C.M.N.N.; SILVA, M.L.N.; CURI, N.; CARDOSO, E.L.; MACEDO, R.L.G.; FERREIRA, M.M.; SOUZA, F.S. Atributos indicadores da qualidade do solo em sistema agrossilvopastoril no noroeste do Estado de Minas Gerais. Science Fortil., v.74, p.45-53, 2007.

SANTOS, H. G. dos; JACOMINE, P. K. T.; ANJOS, L. H. C. dos; OLIVEIRA, V. A. de; LUMBRERAS, J. F.; COELHO, M. R.; ALMEIDA, J. A. de; CUNHA, T. J. F.; OLIVEIRA, J. B. de. Sistema brasileiro de classificação de solos. 3. ed. rev. e ampl. Brasília, DF: Embrapa, 2013. $353 \mathrm{p}$.

SILVA, V. D.; REINERT, D. J.; REICHERT, J. Densidade do solo, atributos químicos e sistema radicular do milho afetados pelo pastejo e manejo do solo. Revista Brasileira de Ciência do Solo, Viçosa, v. 24, n. 1, p.191-199, 2000. 